University for Business and Technology in Kosovo

UBT Knowledge Center

UBT International Conference

2017 UBT International Conference

Oct 28th, 9:00 AM - 10:30 AM

\title{
SMIA: Improving Kosovo's education management system
}

\author{
Lazar Adjijgogov \\ EduSoft, laze@edusoft.com.mk \\ Dejan Stamenov \\ EduSoft,dejan@edusoft.com.mk \\ Edmond Jajaga \\ EduSoft, edmond@edusoft.com.mk
}

Follow this and additional works at: https://knowledgecenter.ubt-uni.net/conference

Part of the Computer Engineering Commons, and the Computer Sciences Commons

\section{Recommended Citation}

Adjijgogov, Lazar; Stamenov, Dejan; and Jajaga, Edmond, "SMIA: Improving Kosovo's education management system" (2017). UBT International Conference. 91.

https://knowledgecenter.ubt-uni.net/conference/2017/all-events/91

This Event is brought to you for free and open access by the Publication and Journals at UBT Knowledge Center. It has been accepted for inclusion in UBT International Conference by an authorized administrator of UBT Knowledge Center. For more information, please contact knowledge.center@ubt-uni.net. 


\title{
SMIA: Improving Kosovo's education management
} system

\author{
Lazar Adjigogov $^{1}$, Dejan Stamenov ${ }^{1}$, Edmond Jajaga ${ }^{2}$ \\ ${ }^{1}$ EduSoft, Stiv Naumov 1/1-1, Skopje, Republic of Macedonia \\ ${ }^{2}$ UBT - Higher Education Institution, Lagjja Kalabria p.n., Prishtina, Kosova \\ \{laze, dejan\}@edusoft.com.mk, edmond.jajaga@ubt-uni.net
}

\begin{abstract}
Successful management of today's education systems requires effective policy-making and system monitoring through data and information. To this end, countries around the world have invested significant resources into collecting, processing, and managing more and better data through education management information systems (EMIS). SMIA is a modern EMIS, which offers easier management of educational process in Kosovo. It facilitates decision-making, resource planning, strategy building, monitoring and evaluation of educational system through a rich set of analytical and statistical tools. For over six years of activity, the system has efficiently tracked and thus helped the development of the educational process for every institution including kindergarten, preprimary, primary and middle school. This paper will describe the system tools and features, which has enabled real-time monitoring of pupils and teachers performance. This information has provided a timely intervention from the high management to make balanced dissemination of didactic resources.
\end{abstract}

Keywords: Information Systems, EMIS, Education, Educational data

\section{Introduction}

The world we are living today, data is incredibly important for any organization because it helps them expose variability and optimize operational costs. Processing large amount of data generated by any system provides the possibility to uncover hidden patterns and correlations. The educational data is constituted from administrative data from different departments in the Ministry of Education, data collected through surveys and assessments. The processing of this data is essential for effective planning of the education, as well as achieving national educational goals. To this end, countries around the world have invested significant resources into collecting, processing and managing more and better data [10].

There are multiple factors that can influence the quality of the data in the education [1]:

- lack of required data collection (in terms of a process of data collection),

- lack of standards and methodologies (based on which the data is collected),

- limited operational capacity (in terms of consolidating data) and

- data processing capacity. 


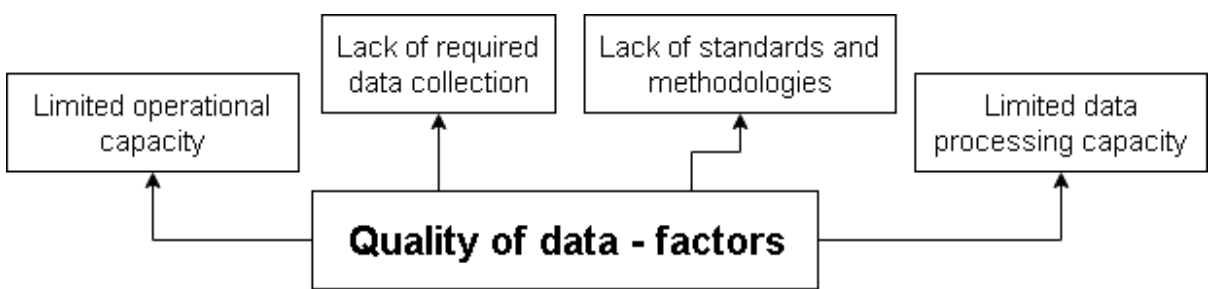

Fig. 3 Visual representation of the factors that can influence the quality of the data in the education

To lower the impact of the factors that influence the quality of the data, Education Management Information System (EMIS) is introduced. As an educational system, it should provide institutional service for unit producing, managing and dissemination of educational data and information. The system itself is a repository for data collection, processing, analyzing and reporting. The data of the EMIS need to be accurate, timely, reliable (may be affected by external factors) and understandable (the challenge of data processing) [2].

The paper is organized as follows. Section 2 provides the related work. Our system and its characteristics are provided in Section 3, while in Section 4 is our future work. Finally, Section 5 summaries the paper contributions.

\section{Related work}

OpenEMIS [4] is an Education Management Information System, initially conceived by UNESCO. The system is created not to just collect, store and process data, but to formulate education policies and their management rules [5]. The system is created to help all the member countries of UNESCO, thus it is an open source software. It is built with modular application design, providing data collection, management and analysis. The downside of this project is the required expertise that a nation needs to have in order to implement the system in the education. Each nation has its own goals that need to be monitored and achieved, which requires database administrators and software engineers to adapt the components of OpenEMIS [6]. Our system is not open source, thus we are providing the expertise for setting up the system, along with all the needed customization to meet the requirements of the nation. The first implementation of the OpenEMIS happened in Malaysia, 2012, followed by Grenada and St. Vincent and the Grenadines in 2013. Belize and Jordan implemented the system later on, at 2014. Maldives made also an implementation of this system in 2015, and the latest to implement it are Turks and Caicos Islands in 2016.

Prodigy [7] is another Education Management Information system, which offers their functionalities based on a subscription. These functionalities include examination system, along with integrated e-Library and e-Diary. SMIA is lacking these functionalities, but as an important factor in the management of the education, our plans are to integrate e-Diary projects with our system. Argentina has its own system too, GoSchool [8]. Project Fedena [9] is also an open source system, implemented by Kerala, with the main focus on the school management and collaboration between students and teachers.

\section{SMIA - Education Management Information System (EMIS)}

We have developed SMIA, a modern education management information system. The system itself facilitates decision-making, resource planning, monitoring and evaluation of the 
educational data. Our system is active in Kosovo's education for over six years, efficiently tracking and developing the educational process for every institution, including kindergarten, preprimary, primary and middle school.

It provides rich set of analytics and statistics tools. Key Performance Indicators (KPIs) are generated ad-hoc, including Gross Enrollment Rate (GER), Gross Intake Ratio (GIR), PupilTeacher Ratio (PTR) and Gross Primary Graduation Ratio (GPGR). SMIA supports complete dossier for all the academic personnel in the educational institutions. Data about the current working position of the teacher, along with the complete working and training history of the person are stored into the database. Predefined reports are available, including the possibility to create custom reports "on the fly". The predefined reports are based on groups for: schools, students, teachers, incidents and subjects. Available reports range from physical state of schools, to qualifications of teachers based on different conditions, number of students in each school registered in the system, travel distances for each student/teacher in the school to their home. Filtering based on nationality, age, genre and so on are available to the end user. The custom reports are based on any model (i.e. school, teacher, student) and can include data based on the current requirements when the report is created. These reports are generated by the administrative users of the system, which allow for specific, custom analysis of the educational data.

The system supports school case registry where the incidents from the educational institutions are recorded. This module holds the details of each accident, starting off with basic information about the accident (school where the accident happened, date and status of the accident) up to the required details of the reporter of the accident, every person involved in it, along with detailed information about the accident.

On Fig.2. are described the most important modules of the application. Data is shared between the modules for the purposes of the educational management system. Currently, the system supports manual and bulk data import. For example, the budget data of each educational institution can be imported from the Ministry of Finances of the country. All the statistics and details about the nation population can be imported from the State Statistical Office. All this data is crucial when calculating the KPIs.

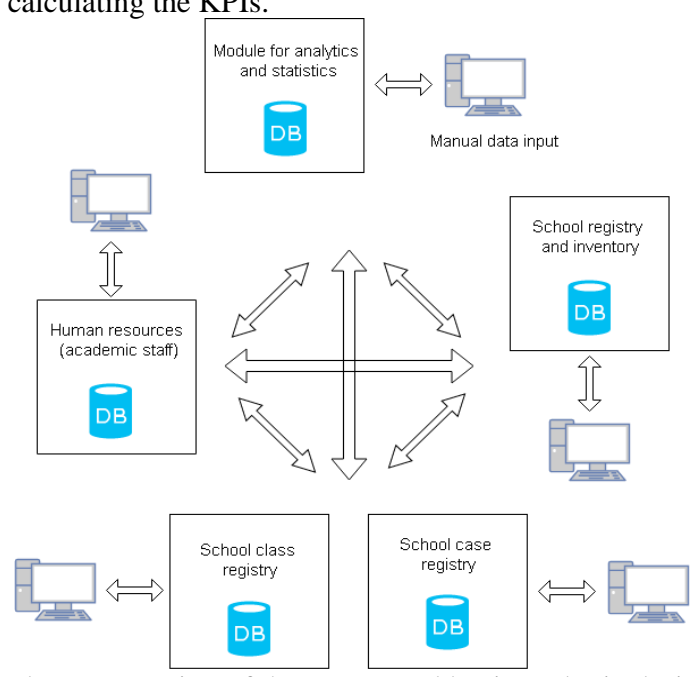

Fig. 4 Visual representation of the conceptual business logic design of SMIA 


\section{Future work}

SMIA supports complete dossier for academic personnel in each educational institution. But, this is not enough. To provide even more data for educational purposes, we need to keep complete dossier data for each student in the nation. We plan to upgrade the system with such functionality, so that the Ministry of Education can have all the details about a particular student, from kindergarten to university level.

The system lacks the educational data from the universities. The data produced by the universities is very important for achieving national educational goals, while also having a huge impact on the education strategy. Our plan is to upgrade the system with new features regarding the university data, while also providing custom reports for the needs of these institutions.

When talking about education strategy and its importance, our plan is to provide such feature in SMIA. That will allow the Ministry of Education to offer a portfolio of subjects across a range of disciplines and to adopt a curriculum to the needs of the nation. In addition to this, it will embrace new and innovative teaching methods, and utilization of technology in terms of enriching learning. Will provide new methods for improving students' assessments and their feedback, while greatly enhancing pedagogic practice.

In the recent years, e-Diary systems are very popular and needed, which provide an alternative to paper school diaries, while also trying to engage parents, support teachers and empower students [3]. As our system stores student data from kindergarten to middle school, we plan to provide a virtual connection with the e-Diary projects, which will provide easier access and import of complete educational data directly from educational institutions, thus avoiding manual input in the system.

As the application is 6 years old, the user interface got outdated with all the changes in the technology industry. Our intentions are to provide an upgraded user interface, which will be much more user friendly, while also providing responsive design to any Internet device.

\section{Conclusion}

In this paper, we have presented the importance of the educational data, and its impact towards meeting national goals, while also building successful national educational strategy. We have introduced SMIA, an Education Management Information System as an important step towards lowering the impact of the factors that influence the quality of the data. The functionality of our EMIS, SMIA was provided, along with our future plans based on the six years of experience in Kosovo's education.

\section{Acknowledgement}

This paper was supported and funded by EduSoft, Skopje, Republic of Macedonia.

\section{References}

1. Unesco (2017) The Data Revolution in Education, pp. 15-16 http://uis.unesco.org/sites/default/files/documents/the-data-revolution-in-education2017-en.pdf, Accessed 21 Nov 2017 
2. Bernbaum, M., \& Moses, K. (2011). Education Management Information Systems. Education Policy and Data Center, p.20

3. MyeDiary, http://www.myediary.com.au/, Accessed 21 Nov 2017

4. OpenEMIS, https://www.openemis.org/, Accessed 21 Nov 2017

5. Unesco Education Management Information System

(EMIS) http://www.unesco.org/new/en/education/themes/planning-and-managingeducation/policy-and-planning/emis/, Accessed 21 Nov 2017

6. Souter, D., Adam, L., Butcher, N., Sibthorpe, C., \& Tusubira, T. (2014). ICTs for Education in Africa, p. 12

7. Prodigy, http://www.prodigy.com.ng, Accessed 21 Nov 2017

8. GoSchool, https://www.goschool.com.ar/, Accessed 21 Nov 2017

9. Project Fedena, http://projectfedena.org/, Accessed 21 Nov 2017

10. Hua, H., \& Herstein, J. (2003, March). Education management information system (EMIS): Integrated data and information systems and their implications in educational management. In annual conference of comparative and International Education Society (p. 26). 